\title{
El bienestar animal como límite constitucional a las expresiones culturales en México. Comentarios a la tesis 163/2018 de la Suprema Corte de Justicia de la Nación
}

\author{
Rosa María De la Torre Torres \\ Investigadora y Profesora de la Facultad de Derecho y Ciencias Sociales de la UMSNH. Fundadora y \\ coordinadora general del Grupo de Investigación en Derecho Animal (GIDA). \\ orcid.org/0000-0003-1696-0770
}

Cita recomendada. DE LA TORRE TORRES, R.M., El bienestar animal como límite constitucional a las expresiones culturales en México. Comentarios a la tesis 163/2018 de la Suprema Corte de Justicia de la Nación, dA. Derecho Animal (Forum of Animal Law Studies) 11/4 (2020). - DOI https://doi.org/10.5565/rev/da.523

\section{Resumen}

La crisis provocada por el SARS-COV2, permite reflexionar sobre la relación entre humanos y animales. Los animales merecen ser tratados con respeto porque son criaturas que experimentan el mundo desde sus propios intereses, en ese sentido, la resolución 163/2018 de la Suprema Corte de Justicia de la Nación sienta un buen precedente.

Palabras clave: bienestar animal; derecho animal; ponderación constitucional; derecho a la cultura; expresiones culturales; principios implícitos; interpretación constitucional.

Abstract - Animal welfare as a constitutional limit to cultural expression in Mexico. Comments on the thesis 163/2018 of The Supreme Court of Justice of the Nation

The crisis provoked by SARS-COV2 allows us to reflect on the relationship between humans and animals. Animals deserve to be treated with respect because they are creatures that experience the world through their own interests; in this sense, The Supreme Court of Justice of the Nation sets a good precedent with resolution $163 / 2018$.

Keywords: animal welfare; animal law; constitutional consideration; right to culture, cultural expressions; implicit principles; constitutional interpretation. 


\section{Sumario}

1. Reflexiones preliminares

2. La interpretación constitucional como mecanismo transformador en favor de los animales

3. Comentarios la resolución 163/2018 de la Suprema Corte de Justicia de la Nación

4. Reflexiones finales

5. Fuentes consultadas

\section{Reflexiones preliminares}

La grave situación sanitaria ocasionada por la proliferación del virus SARS-COV2 ha obligado a hacer una pausa en la vida contemporánea y ha abierto espacios de reflexión importantes que ponen en cuestión muchas de las prácticas sociales y culturales que han fomentado la expansión de la pandemia. Desde esta perspectiva crítica, la cuestión animal cobra relevancia y el maltrato que reciben los animales no humanos utilizados para consumo alimentario es un tema que trasciende el debate ético y gana lugar en las discusiones sobre la salud humana y el medioambiente. En referencia a la pandemia del COVID-19, un interesante artículo publicado por la María Andreata y Silvina Pezzeta señala que:

El incremento observado a nivel global de este tipo de enfermedades se relaciona tanto con la alteración de los entornos naturales como con el hacinamiento que resulta de la cría masiva de ganado para consumo humano. Según estimaciones recientes, alrededor del $60 \%$ de todas las enfermedades infecciosas en los seres humanos son de origen zoonótico. Si bien muchas de ellas se encuentran alojadas en la fauna silvestre, el ganado suele servir de "puente epidemiológico" hacia las poblaciones humanas. ${ }^{1}$

Ahora es más evidente que nunca que las condiciones en que se reproducen y crían los animales para el consumo humano tienen graves efectos en el medio ambiente, en la salud de los propios animales y en consecuencia en la salud humana. Por ello, a decir de la primatóloga Jane Goodall la falta de respeto con la que hemos tratado a los animales es la principal causa de la situación sanitaria actual. ${ }^{2}$

Por su parte, el filósofo Peter Singer ${ }^{3}$ señala que la causa subyacente a la proliferación de diversas enfermedades como el SARS (Síndrome Respiratorio Grave) de 2003 y el propio SARS-COV2, son los "mercados húmedos" de China: espacios en los que se compran animales vivos que son sacrificados en ese mismo sitio para su consumo. Sin embargo, aunque esto pudiera parecer algo exótico a los ojos de las culturas occidentales, los mercados de nuestros países no son muy diferentes en cuanto a las condiciones de reproducción, crianza, transporte y sacrificio de las especies que se venden.

Desde principios de 2020, prácticamente todos los países buscan respuestas para paliar los efectos de la enfermedad que ha tenido un impacto nunca visto en la historia contemporánea. Aunado a lo anterior, los organismos internacionales como la Organización de las Naciones Unidas (ONU) ha señalado que la respuesta a una crisis global debe ser integral. Así, ha publicado el 28 de julio de 2020 el Informe titulado "Armonía con la Naturaleza"4 en el que señala que lo que se ha vivido este año es la "crónica de una pandemia anunciada" ya que hace más de diez años los científicos han advertido de la proliferación de enfermedades transmitidas

1 ANDREATTA, M.- NAVARRO, M.- PEZZETA, S., Pandemia por COVID-19: Un punto de partida para pensar las intersecciones entre especismo, medioambiente y alimentación, en Question, 6 (2020) 355-362 DOI: https://orcid.org/0000-0002-4715-6147

2 Europapress. Jane Goodall: "Nuestra falta de respeto a los animales ha causado la pandemia de coronavirus". Página Web: https://www.europapress.es/cultura/cine-00128/noticia-jane-goodall-falta-respeto-animales-causado-pandemia-coronavirus20200416133432.html

[Última consulta: 24 de mayo de 2020]

3 Project Syndicate. El otro lado oscuro del Covid-19. Página Web: http://www.project-syndicate.org/commentary/wet-marketsbreeding-ground-for-new-coronavirus-by-peter-singer-and-paola-cavalieri-2020-03/spanish [última consulta: 27 de mayo de 2020] 4 Organización de Naciones Unidas. Armonía con la naturaleza. Informe del Secretario General. Página Web: https://undocs.org/es/A/75/266 [Última consulta: 12 de agosto de 2020] 
de animales a humanos derivada de los cambios climáticos y las conductas humanas. Por ello, en el punto 16 del citado Informe expresamente se afirma que:

Las respuestas ante los retos complejos, como la pandemia, el cambio climático y otros retos del Antropoceno, dependen de los valores y las normas por los que se rigen los individuos y las sociedades afectados. La ciencia puede aportar gran cantidad de información y hechos, pero la ciencia moderna se esfuerza por dar explicaciones puramente objetivas y estrictamente factuales y excluye de forma deliberada la influencia de los valores sociales y culturales. ${ }^{5}$

Para el Secretario General de la Organización de Naciones Unidas, los valores sociales y culturales son "fundamentales para el futuro de la humanidad y para la forma en que los seres humanos gestionarán tanto el cambio climático como futuras pandemias". 6 Analizar, desde una perspectiva crítica, los hábitos que configuran nuestra forma de vida debe guiarnos a una reconfiguración de la relación entre los animales y los humanos.

Encontrar el equilibrio resulta imprescindible, por ello, Naciones Unidas señala que:

Si la humanidad está dispuesta a frenar el consumo para proteger la vida en la Tierra de forma genuina y a dejar de considerar la Naturaleza como un objeto que manipular y explotar, es preciso prestar más atención a los valores y a la noción de "necesidades frente a deseos". La recuperación de la COVID-19 es una oportunidad única de generar cambios transformadores, a partir de ahora mismo, y exige prestar atención y apoyo a las iniciativas y los avances en los ámbitos de la economía ecológica y el derecho centrado en la Tierra. ${ }^{7}$

Sin embargo, algunas prácticas sociales en nuestros entornos pretenden justificar la utilización de animales, específicamente para la alimentación y la recreación, en el arraigo cultural que éstas prácticas tienen. El consumo de animales como base de la alimentación es un paradigma muy fuerte en muchas de las sociedades contemporáneas y como señalan Andreatta y Pezetta:

El carnismo proporciona el soporte a un sistema alimentario que ha señalado a la carne como alimento fundamental, sinónimo simbólico de nutrición y de riqueza. El sostenimiento de tal sistema requiere de ciertas estrategias que no permitan a los sujetos conectar "carne" con "animales", y "animales" con "sintiencia"; es decir, pensar en ellos desde un lugar de empatía.

Asimismo, necesita de todo un conjunto de prácticas productivas, como lo son la ganadería y la industria cárnica, así como de los consumos alimentarios de millones de personas que desconocen los procesos y los impactos de éstos en diversas aristas de su vida. Dentro de estos impactos desconocidos, el lugar que ocupó la cría industrial de animales no humanos en la emergencia y la transmisión del COVID-19 es algo que permanece en la total ignorancia para la mayoría de la gente, que sigue asignando culpas a murciélagos o ciudades distantes con culturas diferentes $-\mathrm{y}$ que, por ello, resultan más sencillas de señalar. ${ }^{8}$

Las condiciones sanitarias y de desgaste de nuestro medio ambiente hacen urgente que se reconsideren nuestras prácticas cotidianas. Los animales han perdido paulatinamente su estatus de seres dignos de respeto para convertirse en medios para la obtención de beneficios tanto en la alimentación como en otros muchos aspectos del desarrollo de la vida humana. En la mayoría de las sociedades contemporáneas, los intereses de los animales están subordinados a los intereses de los humanos; así se han establecido las bases de una explotación cruel y desmedida tanto de recursos naturales como de animales.

A lo largo de la historia del pensamiento humano encontramos voces críticas hacia las prácticas crueles hacia los animales. Desde la Grecia clásica llega la voz del poeta Ovidio, quien pone en boca de Pitágoras las siguientes palabras:

Mientras los hombres sigan masacrando a sus hermanos animales, reinará sobre la Tierra la guerra y el sufrimiento, y se matarán los unos a los otros, pues aquel que siembre el dolor y la muerte no podrá

5 Ibidem, p. 4.

6 Idem.

7 Ibidem, p. 5.

8 ANDREATTA, M.- NAVARRO, M.- PEZZETA, S., Pandemia por COVID-19: Un punto de partida para pensar las intersecciones entre especismo, medioambiente y alimentación, en Question, 6 (2020) 4. DOI: https://orcid.org/0000-0002-4715-6147 
cosechar el gozo ni la paz. ${ }^{9}$

El impacto del pensamiento pitagórico en el tema de la consideración ética de los no humanos dejó una impronta indudable, no solamente en sus alumnos y discípulos, sino en los más importantes filósofos clásicos. En este sentido, por ejemplo, Platón siendo gran admirador de la enseñanza del maestro de Samos abrazó el vegetarianismo como una dieta para el cuerpo y para la mente.

Para Plutarco los sufrimientos ociosos, por diversión o por glotonería ocasionados a los animales, sean salvajes o domésticos, resultan injustificados. Es importante destacar la postura ética del autor que se analiza: no muestra reticencia para que le hombre se "sirva" de los no humanos, siempre y cuando lo haga con mesura, con templanza y sin ocasionarles sufrimiento ocioso. Establece un límite moral a la relación humano-animal aunque ésta sea considerada desde la postura antropocéntrica de que los animales pueden estar al "servicio" de los humanos. ${ }^{10}$

Los anteriores ejemplos dan muestra de que la cuestión animal ha sido una constante en las reflexiones que desde la Filosofía y el resto de las disciplinas proponen una relación de equilibrio entre humanos y no humanos. En este mismo sentido argumenta Javier Alfredo Molina Roa:

El interés por la relación jurídica entre el hombre y el animal no es un fenómeno exclusivo de los tiempos modernos; en las diversas etapas de evolución de las sociedades el animal ha sido un protagonista de primer orden en las prácticas jurídicas debido a su cercanía y estrecha relación con los seres humanos, Sin embargo, tal vínculo ha estado marcado por la ambivalencia de sentimientos y actitudes del hombre hacia las especies diferentes, al autoproclamarse el ser dominante del planeta. El dominio de la naturaleza, celebrado en algunas culturas y religiones, e indiferente para otras, ha dado cabida al señorío de los humanos sobre las demás especies animales. ${ }^{11}$

Sin embargo, las tensiones entre los intereses de los animales y los humanos son también una constante en la historia de la humanidad. El trato abusivo que reciben los no humanos solía, hasta hace muy poco, resolverse con argumentos de corte especista en los que la supremacía de lo humano sobre lo animal era evidente. Prácticamente todos los constructos de la mente humana, el Derecho entre ellos, partían de esta especial consideración de los intereses humanos en una esfera de superioridad. Así, muchas de las prácticas crueles se disfrazaron de tradición o de cultura. Los derechos fundamentales fueron utilizados como anclas para permitir y seguir arraigando estas expresiones de crueldad hacia los animales.

Como señala Molina Roa:

No obstante, algunas épocas de la historia se destacaron por la especial relación entre los humanos y los animales, donde las normas y prácticas jurídicas jugaron un papel preponderante, ya fuera para justificar y garantizar desde el derecho múltiples costumbres que implicaban el dominio y total disposición sobre la fauna, cualquiera fuera su clase; la utilización de animales domésticos en actividades diferentes a las tradicionales, como la agricultura y la ganadería; la tortura y muerte a gran escala de especímenes salvajes, como una forma de diversión de gran aceptación social; o su juzgamiento público como reos de crímenes de sangre o causantes de daños patrimoniales, en un particular fenómeno de aplicación del derecho penal y civil, de enorme importancia para entender ciertas dinámicas de control social, donde las normas jurídicas estaban ligadas estrechamente al ethos religioso dominante, como es el caso del cristianismo de la Edad Media europea. ${ }^{12}$

Pese a lo anteriormente expuesto, paulatinamente se plantea un cambio en muchos de los sistemas jurídicos contemporáneos hacia la consideración de los animales no humanos como seres con derecho a ser tratados con respeto. En el Derecho comparado se han dado pasos firmes al reconocer a algunos animales el carácter de seres sintientes, lo que ha permitido considerarles sujetos de derecho y dejar atrás el paradigma que los contempla simplemente como objetos susceptibles de propiedad o cosas. Francia es un ejemplo de lo dicho, al reformar su Código Civil para descosificar a los animales y considerarlos como "seres vivos y sensibles". ${ }^{13}$

9 OVIDIO, Las metamorfosis (Madrid 2012) 12.

10 PLUTARCO, Acerca de comer carne (México 2008) 7.

11 MOLINA ROA, J., Los derechos de los animales. De la cosificación a la zoopolítica (Colombia 2018) 15.

12 Ibidem, p. 17

13 Así resulta de la modificación del artículo 528 del Coódigo Civil operada por el artículo 2 de la LOI n $2015-177$ du 16 février 2015 relative à la modernisation et à la simplification du droit et des procédures dans les domaines de la justice et des affaires intérieures. Véase Pagina Web: https://www.legifrance.gouv.fr/jorf/id/JORFTEXT000030248562/ [Última consulta. 4 de noviembre de 2020]

230 Derecho Animal. Forum of Animal Law Studies, vol. 11/4 
Esta apertura se observa con mayor contundencia en el ámbito jurisprudencial latinoamericano, con relación al reconocimiento de personalidad jurídica no humana, ha incluido en esta consideración a la naturaleza y a los animales no humanos. Las sentencias de los casos judiciales de la orangutana Sandra y la chimpancé Cecilia, quienes fueron reconocidas, a través del Habeas Corpus, como sujetos de derechos por diversos jueces argentinos son resoluciones ejemplares en las que puede observarse cómo el derecho se está adaptando a una demanda creciente para considerar los intereses de los no humanos dentro de los sistemas jurídicos. ${ }^{14}$

En este mismo sentido destaca la resolución que en México emitió el Pleno la Suprema Corte de Justicia de la Nación (en adelante SCJN), donde por unanimidad, se reconoce el bienestar animal como un principio implícito de la Constitución mexicana que puede limitar de manera proporcional y justificada los derechos fundamentales, como el derecho a la participación en la vida cultural y sus variadas expresiones. ${ }^{15}$ En esta sentencia, por primera vez, el sistema judicial mexicano encuentra que la protección y el respeto a los animales es un principio que obliga al Estado mexicano a eliminar todas las formas de abuso y maltrato hacia éstos, aunque ello implique limitar el ejercicio de los derechos humanos.

A reserva de detallar el contenido de la mencionada resolución en apartados subsecuentes de este trabajo, se debe destacar que la SCJN ha afirmado que, aunque existen prácticas culturales muy arraigadas en la sociedad mexicana, no todas están protegidas prima facie por la Constitución ya que si resultan contrarias a los principios implícitos de misma no tendrán protección del sistema constitucional. Dentro de los argumentos vertidos por este órgano jurisdiccional, destaca el reconocimiento del bienestar animal como un principio constitucional implícito que obliga a que se establezcan las medidas conducentes a limitar y erradicar todas aquellas prácticas culturales contrarias al mismo, aun cuando éstas gocen de importante arraigo cultural. Así, en el caso concreto de estudio, la prohibición de las peleas de gallos resulta un límite proporcional y justificado a los derechos de participación en la vida cultural.

Este ejercicio jurisprudencial abre caminos muy interesantes para reflexionar sobre la relación humanoanimal, no solamente en cuanto a expresiones culturales recreativas, sino en ámbitos muy específicos como el consumo alimentario. Si bien, la Suprema Corte de Justicia de la Nación no aborda este tema específicamente, establece el bienestar animal como un límite válido y aplicable a toda práctica cultural humana.

Como se ha señalado, el consumo de animales en la dieta de muchos países se interpreta como una expresión cultural, sin embargo, la crisis del SARS-COV2 nos obliga a repensar muchas de éstas prácticas sociales y culturales. Es un buen momento para asumir que los animales no humanos tienen sus propios intereses de vivir libres de sufrimiento, de enfermedad, de angustia, de vivir en libertad y de desarrollarse acorde a su especie, esto bien podría traducirse en un reconocimiento jurídico de estos intereses convirtiéndolos en derechos. En este orden de ideas es importante recordar lo señalado por Tom Regan en su obra En defensa de los derechos de los Animales:

Así, se ha argumentado en defensa de los derechos de los animales. Si este argumento es sólido, entonces, al igual que nosotros, los animales tienen determinados derechos morales básicos, que incluyen en particular el derecho fundamental a ser tratados con el respeto que, como poseedores de un valor inherente se merecen como asunto de estricta justicia. ${ }^{16}$

Aunque aún estamos lejos de que se reconozcan explícitamente los derechos para los animales, como lo propone Regan, hay importantes avances para sentar bases fuertes jurisprudenciales para desarrollar, posteriormente, el contenido de estos derechos y considerar los intereses de los animales como una expectativa de justicia.

Las condiciones en las que los animales viven en las cadenas de producción industrializada y en los mercados húmedos atentan contra esos intereses y ahora podemos ver muy claramente que también atentan contra los nuestros: las enfermedades que ahora experimentamos son, en buena medida, el resultado del maltrato al que los hemos sometido.

Parece ahora muy claro que los intereses de los animales no humanos y de los humanos convergen en estos momentos: ellos no quieren morir y nosotros tampoco. Tratar con respeto a los animales es el primer

14 Para consultar ambas resoluciones véase respectivamente Sistema Argentino de información jurídica SAIJ. Página web http://www.saij.gob.ar/2786-nacional-prohibicion-malos-tratos-animales-lns0002465-1891-07-25/123456789-0abc-defg-g56-

42000scanyel [Última consulta 26 de mayo, 2020] y Infojus: NV9953 [Http://www.infojus.gob.ar/camara-federal-casacion-penalconsidera-unaorangutana-sumatra-es-sujeto-derechos-nv9953-2014-12-18/123456789-0abc-d35-99ti-lpssedadevon. [Última consulta 24 de mayo de 2020].

15 Suprema Corte de Justicia de la Nación. Amparo en revisión 163/2018. [México] Última consulta 24 de mayo de 2020 https://www.scjn.gob.mx/sites/default/files/listas/documento_dos/2018-10/AR-163-2018-181022.pdf

16 REGAN, T., En defensa de los derechos de los animales (México 2016) 369. 
paso para evitar futuros problemas sanitarios y medioambientales, pero también es la base para construir una mejor sociedad y así lo semana Miguel Sánchez González:

El respeto es la única actitud sabia que cabe adoptar, teniendo en cuenta nuestra ignorancia de las leyes la naturaleza y de nuestro desconocimiento de las consecuencias últimas de nuestros actos. Y desde luego, el respeto hacia los animales no es incompatible con el respeto hacia los seres humanos. Ambos respetos forman parte de un único y más amplio sentimiento de "respeto hacia todo y hacia todos", de modo que cuando se cultiva correctamente uno de estos respetos se cultiva también el otro...

También convendría renunciar al entropocentrismo ético exclusivo. Es preciso reconocer que toda forma de vida es un valor en sí misma que debe ser respetado y protegido. ${ }^{17}$

La pandemia ocasionada por el virus SARS-COV2 nos obliga a repensar y reconstruir nuevas formas de comunicación social y política, reconsiderando nuestros hábitos de consumo en general. Es momento de señalar que, además de los daños que ocasionan en la salud humana los abusos cometidos en la cría intensiva de animales para el consumo humano, éstos merecen ser tratados con respeto porque, además de ser capaces de sufrir son criaturas que experimentan el mundo desde sus propios intereses y en este sentido, la resolución 163/2018 de la Suprema Corte de Justicia de la Nación sienta un muy buen precedente.

\section{La interpretación constitucional como mecanismo transformador en favor de los animales}

El contenido esencial de las constituciones no es estático, ni los derechos fundamentales contenidos en ellas son ilimitados. La norma fundamental debe estar integrada por reglas y normas, evidentemente, pero también por principios y valores que orienten el desarrollo de las normas secundarias y de las políticas públicas, así como la interpretación jurisprudencial del contenido de la constitución $\mathrm{y}$, entre estos principios, puede encontrarse el respeto y la protección del bienestar de los animales. En este orden de ideas, la postura de Joaquín Brage Camazano es muy ilustrativa para el caso que nos ocupa:

Ahora bien, a nuestro juicio, la exigencia de que un bien o derecho tenga rango constitucional no obsta a considerar a la protección de los animales como un posible límite legítimo a los derechos fundamentales, ya que la misma puede considerarse un fin de rango constitucional (aunque no totalmente expreso ni directo, sino implícito e indirecto), pues para ello bastan, en una interpretación de conjunto, las normas que establecen las competencias del Estado o las comunidades autónomas sobre la ganadería, la pesca, caza marisqueo, acuicultura, y el medio ambiente, así como el propio derecho a un medio ambiente adecuado y a la utilización racional de los recursos naturales (lo que incluye a la fauna, como uno de los reinos clásicos de la naturaleza), pues creemos que las normas competenciales pueden habilitar restricciones a los derechos fundamentales en cuanto que encierren un interés no neutral de la Constitución por la protección amparo de ciertos bienes jurídicos. Esto significa que la protección de los animales es un fin de rango constitucional, hábil, pues, en abstracto, para restringir derechos fundamentales, siendo cuestión distinta que sea hábil (sin entrar ahora en si la restricción es o no proporcionada) para restringir uno $\mathrm{u}$ otro derecho fundamental en concreto en un determinado caso o supuesto, que es algo a determinar caso a caso (así, por ejemplo, será más fácil encuadrar a la protección de animales entre los derechos de todo el título I como límite de las libertades del artículo 20, CE, o entre el "orden público con peligro para personas y bienes" como límite de la libertad religiosa, por ejemplo). ${ }^{18}$

En consonancia con lo expuesto por el profesor Brage, en los últimos años se percibe un impulso, en varios sistemas constitucionales, de ampliar su esfera protectora incluyendo, además de a los seres humanos, a la naturaleza y a los animales no humanos. Así, observamos un cambio paulatino de paradigma en cuanto al trato que reciben la naturaleza y los animales desde la perspectiva constitucional.

En el primer caso, hay constituciones y resoluciones de tribunales constitucionales muy importantes que reconocen a la naturaleza como sujeto de protección por su valor en sí misma y no exclusivamente como hábitat del ser humano, como señala Silvia Bagni:

La indisoluble relación entre pobreza y crisis ecológica ha sido subrayada por la mayoría de los estudios

17 SÁNCHEZ GONZÁLEZ, M.A., El debate ético actual sobre la relación del hombre con los animales, en Los derechos de los animales (Madrid 2002) 131.

18 BRAGE CAMAZANO, J., Doménech Pascual, Gabriel, Bienestar animal contra derechos fundamentales, en Boletín Mexicano de Derecho Comparado, Volumen 41 (2008) 1120.

232 Derecho Animal. Forum of Animal Law Studies, vol. 11/4 
sociales críticos que defienden la emersión de nuevos paradigmas epistemológicos fundados desde el Sur, a través de la recuperación de tradiciones culturales autóctonas, siempre vinculadas a una relación armónica, y no jerárquica o de explotación entre el ser humano y la Naturaleza.

En el ámbito jurídico, esta visión crítica implica un replanteamiento de las tradicionales categorías del derecho del medioambiente, a partir de una perspectiva no antropocéntrica, sino bio o ecocéntrica. El cambio de perspectiva permite avanzar en la idea de una nueva dogmática de los derechos, que incluye también, entre los sujetos jurídicos, seres no humanos, como la Naturaleza en sí misma o sus propios componentes. ${ }^{19}$

Es evidente, que el cambio de perspectiva constitucional va girando desde un antropocentrismo, en el que el hombre es la medida de todas las cosas, hacia un biocentrismo en el que se reconoce que hay vida valiosa más allá de la humana. ${ }^{20}$ Este viraje es importante para el tema que nos ocupa ya que es la puerta de entrada por la que se han ido incorporando algunas normas de protección y bienestar hacia los animales no humanos.

En la actualidad, algunas constitucionales naciones, e incluso subnacionales como la de la Ciudad de México, han reconocido a los animales como seres sintientes, en un intento por descosificarlos y por elevar la categoría de protección jurídica correspondiente generando obligaciones de protección desde la esfera constitucional pero sin reconocerles explícitamente derechos. ${ }^{21}$ Aunado a lo anterior, la interpretación constitucional también ha sentado bases importantes, aunque de manera aislada y muy esporádica, para ir cambiando la perspectiva tradicionalmente civilista que considera a los animales no humanos como objetos de propiedad hacia una postura en la que se les considera como seres con capacidad de sentir sufrimiento y dolor, lo cual deriva en importantes obligaciones morales y jurídicas.

Uno de los ejemplos más destacables es la resolución del juzgado $\mathrm{N}^{\circ} 4$ en lo Contencioso Administrativo y Tributario de la Ciudad de Buenos Aires que reconoció a la orangutana Sandra como un "sujeto de derecho", conforme a lo dispuesto por la ley 14.346 y el Código Civil y Comercial de la Nación Argentina. En este caso, la jueza Elena Liberatori señala con acierto que la categorización de Sandra como "persona no humana" y en consecuencia como sujeto de derechos no debe llevar a la afirmación apresurada y descontextualizada de que Sandra entonces es titular de los derechos de las personas humanas. ${ }^{22}$

La interpretación constitucional, se considera como un mecanismo de garantía de los derechos para su protección y desarrollo. En el caso que nos ocupa, la Suprema Corte de la Nación en México ha interpretado que dentro del texto constitucional subyacen una serie de principios implícitos que sustentan el Estado democrático. Tales valores son, entre otros, el pluralismo, el respeto a la dignidad humana y a la naturaleza, y según interpreta la SCJN, el bienestar y la protección de los animales resulta también un principio constitucional que obliga a establecer medidas para procurarles su bienestar y evitarles el sufrimiento innecesario.

Como he apuntado, este tipo de reconocimiento jurisprudencial implica, la posibilidad de colisión entre los principios constitucionales a favor de la naturaleza y los animales y los derechos humanos, por ello resulta imprescindible contar con elementos de ponderación en estos eventuales conflictos.

La dinámica constitucional se caracteriza por una constante colisión de los derechos con otros, o con principios y valores contenidos en el mismo texto constitucional. Estos "choques" no son sino la evidencia de un sistema constitucional "vivo" y corresponde a los intérpretes de la Carta constitucional dirimir tales controversias en ejercicios de ponderación en cada caso concreto. Estos esfuerzos hermenéuticos, reclaman que el juez constitucional haga un estudio profundo del contenido esencial de los derechos, valores o principios en conflicto y pueda armonizar en la medida de lo posible las prerrogativas de las partes en conflicto. Así, podemos encontrar colisiones entre el bienestar animal, como principio implícito y derechos humanos como el derecho a la cultura y a la participación en la vida cultura, el derecho a la libre empresa, el derecho al trabajo, el derecho de propiedad, entre otros.

El tema que se analiza en el presente trabajo es, precisamente, la colisión entre el derecho a la cultura

19 BAGNI, S., Los derechos de la naturaleza en la jurisprudencia colombiana e indiana, en Revista Jurídica de Derecho, Volumen 7 (2018) 33 y 34.

20 MARTÍNEZ E. y ACOSTA A., Los derechos de la naturaleza como puerta de entrada a otro mundo posible, en Revista Direito e Práxis, Vol. 8 (2001) 2927.

21 En México destaca la incorporación, dentro de la Constitución de la Ciudad de México, en el artículo 13. B del reconocimiento de los animales como seres sintientes lo que deriva en la obligación de darles un trato digno. Página Web: http://www.infodf.org.mx/documentospdf/constitucion_cdmx/Constitucion_\%20Politica_CDMX.pdf[Última consulta 27 de mayo de 2020].

22 INFOJUS: NV9953. Página Web: Http://www.infojus.gob.ar/camara-federal-casacion-penal-considera-unaorangutana-sumatraes-sujeto-derechos-nv9953-2014-12-18/123456789-0abc-d35-99ti-lpssedadevon. [Última consulta 24 de mayo de 2020]. 
y a la participación en la vida cultural y el principio implícito de protección al bienestar animal que la SCJN en México ha delineado con mucha claridad en la resolución 163/2018.

En ésta época, en la que una pandemia sanitaria como la del SARS-COV2 nos obliga a repensar la manera en que nos relacionamos con los animales no humanos, surgen, aún en medio de la crisis, voces que pretenden defender el abuso y explotación a la que se somete a éstos argumentando que se tratan de expresiones culturales, como las culinarias, profundamente arraigadas en determinadas sociedades. Así, para muchos sigue siendo incontestable el hecho de que en China existan mercados húmedos donde se consuman animales exóticos recién sacrificados, como resulta incontestable para otros, el consumo de animales producidos en cadenas industrializadas que no difieren mucho de los mercados húmedos de China.

En la mayoría de los países se puede observar que dentro de las expresiones culturales la relación humano-animal está presente y no siempre de manera agradable para éstos últimos. En cada sociedad que se estudie con un poco de detenimiento es posible observar prácticas que implican la crueldad y el maltrato hacia los animales las cuales se justifican en el profundo arraigo que éstas tienen. Así, encontramos que los animales son abusados en fiestas populares, espectáculos públicos, ritos de carácter religioso, ejercicios culinarios y la práctica de las medicinas tradicionales, solamente por mencionar algunos.

Para establecer bases claras en aras de mejorar el trato que reciben los animales no humanos en nuestro entorno resulta importante contar con argumentos sólidos, desde los más altos tribunales de interpretación constitucional, que arrojen luz sobre estos debates y por ello la resolución 163/2018 de la SCJN en México es un precedente fundamental que establece criterios claros sobre la colisión entre el derecho a la cultura y la protección al bienestar de los animales. Así, se puede afirmar que México cuenta ahora con pautas claras para la resolución de conflictos y colisiones entre los derechos humanos y el bienestar y protección de los animales.

En la resolución que se comenta se define el bienestar animal como una finalidad compatible con los valores propios de una democracia constitucional por lo que representa un límite fundado y proporcional al derecho a la cultura, el derecho de propiedad y la libertad de trabajo y empresa entre otros derechos.

Una vez que se ha establecido que el bienestar animal es un principio constitucional implícito, la doctrina sugiere, al aplicar a cada caso concreto someter la aplicación de los principios como límites a los derechos a un conjunto de pruebas y análisis para determinar la idoneidad, la legitimidad y la proporcionalidad de las limitaciones impuestas a la luz del bien jurídico superior protegido. En este punto resulta recomendable recordar las palabras de Joaquín Brage:

Es decir, la Constitución no exige, para que una restricción a un derecho fundamental sea legítima, que la misma respete la reserva de ley o esté prevista en una norma general o irretroactiva, o persiga un fin constitucional, o sea adecuada o idónea, o sea necesaria - es decir proporcionada - en sentido estricto, o no viole su contenido esencial, etcétera, sino que la Constitución exige que respeten todos y cada uno de esos requisitos, y por ello hay que analizar su concurrencia de un modo escalonado. ${ }^{23}$

Por lo anterior, la Suprema Corte de Justicia de la Nación sometió al análisis de proporcionalidad las afectaciones señaladas por los demandantes al derecho a la cultura, a la libertad de trabajo y el derecho a la propiedad, analizando si los artículos impugnados inciden en el contenido prima facie de dichas prerrogativas. Así mismo, analizó si las normas combatidas tienen una finalidad legítima y, también, sometió al test de idoneidad, necesidad y proporcionalidad las medidas legislativas impugnadas.

Con el profundo análisis que hace la SCJN para la resolución del caso planteado, se emplea también una metodología clara que permite ponderar la colisión entre la protección al bienestar animal con los derechos que los demandantes consideraron violentados por la prohibición de organizar y desarrollar peleas de gallos. En cuanto a la idoneidad de la medida, la Corte afirma que esta prohibición coadyuva a procurar el bienestar animal evitando el maltrato y la crueldad y que no se afecta directamente a las personas sino a los animales y, citando la doctrina afirma que: "No puede ignorarse que las sociedades acogen manifestaciones festivas irrespetuosas con los animales, herederas de un tiempo donde la soberbia del ser humano negaba cualquier tipo de tregua que pusiera en duda el incontestable dominio sobre los animales no humanos". ${ }^{24}$

Resulta fundamental destacar que la Corte no niega el arraigo que tienen las peleas de gallos en la sociedad mexicana y que incluso, éstas puedan suscitar el interés del arte o ser objeto de estudio en Ciencias Sociales como la Antropología. Sin embargo, estas raíces culturales no justifican que se consideren como prácticas culturales válidas a la luz de los valores democráticos y por ello, a juicio del Pleno de la SCJN, no son dignas de protección constitucional y deben erradicarse.

23 BRAGE CAMAZANO, J., Doménech Pascual, Gabriel, Bienestar animal contra derechos fundamentales, en Boletín Mexicano de Derecho Comparado, Volumen 41 (2008) 1121.

24 GOMEZ PELLÓN E., Los problemas del patrimonio inmaterial: uso y abuso de los animales en España, en Revista de Antropología Iberoamericana, Vol. 12 (Madrid 2017) 148. 
Lo dicho por la Corte es muestra de una tendencia que poco a poco gana terreno en el debate jurídico: el reconocimiento de la protección del bienestar animal como eje de la actuación ética y jurídica.

\section{Comentarios la resolución 163/2018 de la Suprema Corte de Justicia de la Nación}

En octubre de 2018, el Pleno de la Suprema Corte de Justicia de la Nación aprobó, por unanimidad, la resolución $163 / 2018^{25}$, la cual sienta un importante precedente en materia de interpretación y desarrollo constitucional del bienestar animal como principio implícito en la Constitución mexicana.

En 2016, el Congreso del Estado de Veracruz Llave, aprobó reformas a la Ley de Protección a los Animales entre las cuales se prohíben las peleas de gallos por considerarlas como un ejercicio de maltrato y tortura animal. Derivado de lo anterior, la Comisión Mexicana de Promoción Gallística, asociación que representa a más de 40 empresarios galleros, promovió una demanda de amparo en contra de las modificaciones a la Ley de Protección a los Animales para el Estado de Veracruz, contenidas en el Decreto 924 que reforma y adiciona diversos artículos de dicha ley, publicado el 10 de noviembre de 2016 en la Gaceta Oficial del Estado de Veracruz ${ }^{26}$ por considerar que violentaba el derecho a la cultura, el derecho de propiedad de los gallos, la libertad de empresa y de trabajo del gremio gallístico, el principio de igualdad y no discriminación, el principio de progresividad de los derechos y los principios de certeza y seguridad jurídicas.

Para los demandantes, la prohibición que se deriva de la aprobación de los artículos $2^{\circ}, 3^{\circ}$ y 28 de la Ley de protección a los animales para el Estado de Veracruz de Ignacio de La Llave, afectaba varios de sus derechos fundamentales tales como la libertad, el principio de progresividad, la libertad de trabajo, el principio de seguridad jurídica y legalidad, el derecho a la cultural, el principio de igualdad y no discriminación, entre otros.

Dada la trascendencia de los argumentos construidos por la Corte es preciso analizarlos por separado, haciendo un breve recuento sobre los conceptos de violación y una exposición más detallada sobre la colisión con el Derecho a la cultura, que es el tema central de esta exposición.

Uno de los primeros argumentos que esgrimieron los demandantes fue el relativo a que si se prohíben las peleas de gallos se pone en grave riesgo la supervivencia de éstas aves como especie ya que la existencia de éstos espectáculos promueve la subsistencia de criaderos en los que se cuidan a las aves de combate. Según los argumentos vertidos en la demanda (sobre los cuales no presentaron evidencia alguna), existen estudios que demuestran que las aves de combate pelean entre ellas por instinto y se afirma que de desaparecer estos criaderos se pondría en riesgo la conservación de esta especie.

Sobre la pretensión de una afectación económica, derivada de la prohibición de lucrar con las peleas de gallos, los litigantes señalaron que se genera una importante derrama económica, a través de fuentes de trabajo, directas e indirectas, relacionadas con las peleas de gallos. Entre estos argumentos destaca el relativo a las pérdidas que podría representar, en la industria de la producción de navajas, la cancelación de estos espectáculos. Sin embargo, sobre estos dichos tampoco se aportaron pruebas suficientes.

Otro de los conceptos de violación argumentados en la demanda de amparo fue el relativo a al derecho de propiedad. En este argumento los demandantes señalan que para ellos es un error que el legislador del Estado de Veracruz pretenda otorgar la categoría de sujetos de derechos a los gallos porque desde perspectiva son solamente objetos de propiedad por lo que consideran que al prohibir las peleas se está limitando el uso y disfrute de los objetos de propiedad que son los gallos. En este mismo orden de ideas, en la demanda se invoca el artículo 21 de la Convención Americana sobre Derechos Humanos. ${ }^{27}$

Aunado a lo anterior, los actores consideraron violados es la libertad de trabajo al argumentar que la legislación impugnada impide a las personas que se dedican a organizar combates de gallos elegir libremente su profesión y área de trabajo. En consecuencia, a decir de los quejosos, se incumplía la obligación de promover, respetar, proteger y garantizar los derechos humanos, vulnerándose el principio de progresividad, pues la reforma representa un retroceso en materia de libertad laboral.

Finalmente, se debe señalar que el legislador veracruzano estableció como excepciones a la prohibición de peleas y espectáculos con animales todo lo relacionado con la charrería, las corridas de toros y los jaripeos.

25 Suprema Corte de Justicia de la Nación. Amparo en revisión 163/2018 [México]. Última consulta 24 de mayo de 2020 https://www.scjn.gob.mx/sites/default/files/listas/documento_dos/2018-10/AR-163-2018-181022.pdf [Última consulta: 22 de mayo de 2020].

26 Idem.

27 Artículo 21. Derecho a la Propiedad Privada. 1. Toda persona tiene derecho al uso y goce de sus bienes. La ley puede subordinar tal uso y goce al interés social. 2. Ninguna persona puede ser privada de sus bienes, excepto mediante el pago de indemnización justa, por razones de utilidad pública o de interés social y en los casos y según las formas establecidas por la ley. 3. Tanto la usura como cualquier otra forma de explotación del hombre por el hombre, deben ser prohibidas por la ley.Convención Americana sobre Derechos Humanos. Página Web: https://www.oas.org/dil/esp/tratados_b-32_convencion_americana_sobre_derechos_humanos.htm [Última consulta: 3 de noviembre de 2020]. 
En este sentido, los demandantes argumentaron que se violentaba su derecho a la igualdad y al principio de no discriminación ya que se establecía una diferencia injustificada entre las peleas de gallos y las corridas de toros. Incluso, llegan a afirmar los propios demandantes que las peleas de gallos son igualmente crueles que las corridas de toros, es destacable esta afirmación en la que los actores de la demanda admiten la crueldad de su "empresa".

El encargado de resolver, en una primera instancia, esta demanda de amparo fue el Juez de Distrito Décimo Séptimo del Estado de Veracruz quien consideró que las disposiciones impugnadas tienen como objetivo impedir la crueldad animal, a fin de fomentar una cultura en favor del medio ambiente por lo que resultan límites justificados a los derechos que los demandantes consideran vulnerados y así dictó sentencia el 5 de junio de 2017, en la que resolvió negar el amparo y protección solicitada sosteniendo la "prohibición de toda acción que incite, obligue, coaccione, dañe, lesione, mutile o provoque la muerte de este tipo de aves, por ser considerada una conducta antisocial" ${ }^{28}$ No conforme con la decisión del Juez de Distrito Décimo Séptimo de Veracruz, la Comisión de Promoción Gallística de México, solicitó la revisión de la sentencia, en febrero de $2018 .^{29}$

El objetivo de la SCJN, al resolver el recurso, fue determinar en primer lugar si la legislación impugnada limitaba los derechos fundamentales y humanos de los demandantes. En un segundo lugar, la Corte determinó si dichos límites resultaban proporcionales y justificados. Para la revisión de los argumentos se empleó la metodología del test de proporcionalidad, este examen de constitucionalidad de los artículos impugnados se centró en los derechos planteados en la demanda de amparo, es decir, el derecho a la cultura, derecho a la propiedad y libertad de trabajo. Finalmente, se analizó el agravio a lo relacionado con la vulneración al derecho a la igualdad y al principio de no discriminación. Del estudio y análisis del recurso de revisión ${ }^{30}$, la Suprema Corte formuló una serie de razonamientos que delimitan claramente la naturaleza y alcance tanto de los derechos y principios en conflicto como de las normas impugnadas.

Resulta interesante observar que los argumentos que la Corte construye sobre cada una de éstas prerrogativas tienen como tamiz el principio de bienestar animal como principio constitucional implícito, esto es relevante porque se incluye, por primera vez en la historia constitucional de México, dentro de los valores que orientan al sistema constitucional mexicano ${ }^{31}$ al bienestar animal como principio implícito derivado del respeto a la naturaleza y todos los seres sintientes.

A diferencia de lo que el Juez de Distrito consideró, para la SCJN la protección al medio ambiente no puede equipararse con la protección del bienestar animal, porque existen muchas especies que son reproducidos por los seres humanos con distintos propósitos: alimentación, experimentación para fines médicos o científicos, compañía o ayuda a las personas, entretenimiento, entre otros que no son objeto de protección como especies relevantes para la conservación de la biodiversidad.

Así, la protección de toda la vida animal, no es una cuestión que pueda reconducirse necesariamente y exclusivamente a la protección del medio ambiente. Este argumento es muy importante porque se afirma que en México existe ya una categoría de animales especialmente considerada por la ley que son las especies protegidas por las normas que tutelan la biodiversidad, sin embargo, para la Corte, las demás especies que no encuadran en esta categoría como especies protegidas también merecen la consideración constitucional de una protección, independientemente de que sean criadas por los seres humanos para su explotación como animales de consumo alimentario o recreativo.

Referente al derecho a la cultura la SCJN desarrolla argumentos muy profundos que sirven para establecer que si bien existen prácticas culturales muy arraigadas en la sociedad esto no es suficiente para considerarlas protegidas prima facie por la Constitución.

La Suprema Corte de Justicia de la Nación afirma que ciertas expresiones culturales derivadas de la tradición o de la costumbre no pueden tener cobijo en una constitución como la mexicana que asume valores democráticos implícitos como el pluralismo, el respeto a la dignidad y autonomía de las personas.

Aunado a lo anterior, la Corte afirma en la resolución 163/2018 que debe entenderse que existe un mandato constitucional ineludible de erradicar muchas expresiones culturales como la violencia de género, la discriminación o la intolerancia religiosa, por mencionar algunas, dado que resultan contrarias a los valores y principios implícitos de la Carta Magna mexicana.

Los recurrentes sostuvieron que la prohibición de las peleas de gallos vulneraba el derecho a la cultura

28 Poder Judicial Federal. Juzgado Décimo Séptimo del Estado de Veracruz. México. Expediente 1303/2016. Sentencia de Juicio de Amparo. [Última consulta: 19 de mayo de 2020]

29 Suprema Corte de Justicia de la Nación. Amparo en revisión 163/2018 [México]. Última consulta 24 de mayo de 2020 https://www.scjn.gob.mx/sites/default/files/listas/documento_dos/2018-10/AR-163-2018-181022.pdf [Última consulta: 22 de mayo de 2020].

30 Idem.

31 En resoluciones diversas la Suprema Corte de Justicia de la Nación ha señalado que en la Constitución mexicana subyacen los valores democráticos como el pluralismo y el respeto a la dignidad y autonomía de las personas. 
porque éstas son un espectáculo público que por tradición se realiza en las fiestas patronales del Estado. En criterio de la SCJN, el agravio de los recurrentes es infundado pues las reformas a la Ley de Protección a los Animales para el Estado de Veracruz son una medida legislativa que no supone una intervención en el derecho a la cultura.

La SCJN, en el examen de constitucionalidad procedió a determinar si las peleas de gallos constituyen una "expresión cultural" amparada prima facie por el derecho a participar en la vida cultural. Dentro de sus argumentos, señaló que es evidente que algunas sociedades humanas acogen manifestaciones culturales irrespetuosas con los animales por lo que la cultura no es admirable simplemente por ser tradicional o por tener un profundo arraigo histórico o social y solamente tendrá protección constitucional cuando sea portadora de principios que sean compatibles con los valores democráticos. En este sentido, cualquier práctica que suponga el maltrato y el sufrimiento innecesario de los animales, no puede considerarse como una expresión cultural amparada ni prima facie ni de manera definitiva por la Constitución.

Aunado a lo anterior, resulta para la SCJN infundado el argumento de los recurrentes en el que aducen que no se produce ningún maltrato a los animales porque los gallos pelean por instinto, es evidente que las peleas de gallos son una actividad en la que se propicia que los animales se inflijan daños físicos y además se lucra con ello.

Siguiendo la construcción argumentativa de la Corte, no toda expresión o práctica cultural está protegida prima facie por la Constitución mexicana y dado que existe un mandato ineludible de proscribir cualquier práctica que atente contra los valores democráticos resulta legítima la prohibición de aquellas prácticas y expresiones culturales que supongan el maltrato y el sufrimiento innecesarios para los animales no humanos como las peleas de gallos.

Por lo que se refiere a la libertad de trabajo, la SCJN señaló que la libertad de trabajo es un derecho vinculado claramente con la autonomía personal, en la medida en la que permite a los individuos dedicarse a la actividad profesional que mejor se adapte a su plan de vida.

Es importante destacar que la Suprema Corte también ha aclarado que regular una actividad no comporta una vulneración a la libertad de trabajo, los derechos fundamentales no son absolutos, pues se condiciona a la satisfacción de determinados presupuestos fundamentales: a) que no se trate de una actividad ilícita: b) que no se afecten derechos de terceros; y, c) que no se afecten derechos de la sociedad en general.

Para la Corte los alcances de la limitación a la libertad del trabajo derivada de las normas impugnadas también son legítimamente acotados, puesto que no se prohíbe una amplia gama de actividades, sino exclusivamente dedicarse a una muy concreta: realizar peleas de animales y dicha limitación resulta fundada y congruente con la finalidad que persigue la legislación en materia de protección de los animales: evitar el maltrato y el sufrimiento innecesario de los mismos. En este orden de ideas, la Corte afirma que la prohibición de esta actividad, y la consecuente limitación a la libertad de trabajo de los galleros, resulta ineludible por ser la única medida idónea para asegurar el bienestar de los gallos.

Los actores de la demanda de amparo se quejaron de la prohibición de realizar peleas de gallos argumentando que es una medida que no responde a ningún interés público y que limita el uso y disfrute de los bienes de su propiedad, en este caso, los gallos. La Corte al resolver sobre este rubro reconoce que hay una tendencia mundial para modificar el estatus jurídico de los animales no humanos en las leyes que rigen la propiedad privada. En este sentido la SCJN observa que se tiende a reconocer a los animales no humanos como seres sintientes lo cual puede llegar a limitar legítimamente lo que una persona puede hacer o no con los animales bajo su propiedad. En el caso de las normas impugnadas y para determinar si existe una intervención en el contenido prima facie de esta garantía se contrastaron dos cuestiones: si la medida está prevista en una norma general con vocación de permanencia; y si afecta alguno de los atributos de la propiedad privada: uso, goce y disposición.

Para la SCJN los propietarios de los gallos conservan sin ninguna restricción la posibilidad de disponer de las aves, al tiempo que el uso y el goce de las mismas exclusivamente se restringen en relación con una actividad: su uso en las peleas.

Si bien, la protección del bienestar de los animales no es una finalidad ordenada explícitamente en la Constitución para la SCJN ello no supone que deba entenderse que está prohibida constitucionalmente por lo que legítimamente puede justificar la limitación de derechos fundamentales de las personas, como la garantía a la propiedad y la libertad de trabajo. La Corte considera que la prohibición de realizar peleas de animales resulta una medida idónea para proteger el bienestar animal, toda vez que la conducta prohibida les causa daños físicos y sufrimiento innecesario.

Por lo que se refiere a las violaciones al principio de no discriminación y al derecho a la igualdad referidas por los demandantes, es pertinente recordar que el artículo $2^{\circ}$ de la Ley de Protección a los Animales para el Estado de Veracruz, señala que quedan excluidos de la aplicación de la misma, los espectáculos de tauromaquia, faenas camperas, las carreras de caballos, actividades relacionadas con el deporte de la charrería 
y los jaripeos, lo que según los demandantes se traduce en la violación al principio de no discriminación que se establece un trato diferenciado de manera injustificada entre las peleas de gallos y las corridas de toros. A este respecto, la SCJN señaló que el término discriminación se utiliza para hacer referencia a la existencia de un trato diferenciado no justificado, de tal manera que prácticamente se equipara la discriminación con la vulneración del principio de igualdad formal. Así, no basta un trato diferenciado para poder sostener que existe discriminación, se requiere además que la distinción se funde en un prejuicio negativo en virtud del cual los miembros de un grupo son tratados no ya diferentes sino inferiores y fortalece su argumento al señalar que "los galleros" 32 no son un grupo social históricamente discriminado y que la diferenciación legal no incurre en ninguna de las categorías sospechosas en materia de discriminación.

Aunado a lo anterior, el máximo tribunal afirma que pretender que se incluya a las peleas de gallos en la lista de actividades permitidas contemplada en el artículo impugnado con el argumento de que son sustancialmente equivalentes a las corridas de toros, es un argumento que debe rechazarse, los quejosos no pueden beneficiarse de que el legislador haya sido incongruente al incluir una actividad que no debería estar contemplada entre las actividades permitidas por la ley.

\section{Reflexiones finales}

Los argumentos construidos por la Suprema Corte de Justicia de la Nación en la resolución 163/2018, reflejan un cambio de paradigma respecto a la configuración ética y jurídica de la relación humano-animal en el Derecho mexicano. Al interpretar la protección del bienestar animal como un principio explícito en la Constitución mexicana, la Corte, otorga un nivel de vinculatoriedad importante a dicho principio que puede entonces constituir un límite justificado y proporcional para el ejercicio de otros derechos fundamentales y humanos.

Desde esta perspectiva jurisprudencial, la protección de los animales es un objetivo de la sociedad libre y democrática y por ello ha resuelto que la prohibición de realizar peleas de animales es una medida idónea y necesaria para proteger el bienestar animal. Lo anterior se reafirma cuando la SCJN señala que ninguna práctica o expresión cultural que suponga el maltrato y el sufrimiento innecesario de los animales tiene protección en la Constitución mexicana y de ello deriva la obligación judicial, moral y ética de erradicar cualquier práctica que atente contra los valores democráticos, como el pluralismo, la dignidad de las personas y entre los que se incluye el respeto al bienestar y la protección de los animales.

Siguiendo el principio de progresividad en la interpretación judicial, esta resolución puede contener un efecto expansivo, al declarar la protección del bienestar animal como límite legítimo del derecho a la cultura puede considerarse que este efecto lo será frente a todas las expresiones culturales, no solamente deportivas o recreativas, en las que se causen sufrimiento y maltrato innecesario a los animales. Así, está sentencia abre la puerta a impugnar por la vía judicial otro tipo de prácticas como las culinarias en las que los animales son maltratados sin límite ni consideración ética alguna.

En tiempos como los actuales, en las que un virus nos obliga a repensar sobre nuestras prácticas y costumbres más arraigadas, es un buen momento para reconsiderar el trato que reciben los animales criados para consumo humano alimentario.

Como ya lo han señalado muchos científicos, si no modificamos nuestros hábitos de consumo alimentario, el planeta, los animales y nosotros sufriremos las consecuencias.

Los cambios jurídicos deben responden a la realidad social, hoy nuestras sociedades reclaman un trato más digno para los animales y el establecimiento de principios éticos en la configuración de nuestra interacción humano-animal. Por eso, una sentencia como la que se ha comentado, es un instrumento invaluable de cara a transformar el trato que damos a los animales, ahora más que nunca, una cuestión impostergable.

\section{Fuentes consultadas}

\section{Fuentes Bibliográficas}

- ANDREATTA, M.- NAVARRO, M.- PEZZETA, S., Pandemia por COVID-19: Un punto de partida para pensar las intersecciones entre especismo, medioambiente y alimentación, en Question, Volumen 6 (2020), 355-362 (DOI: https://orcid.org/0000-0002-4715-6147) https://ri.conicet.gov.ar/bitstream/handle/11336/107726/CONICET_Digital_Nro.b3b8fed2-61ad40ea-8c32-227b4ff1dcf7_A.pdf?sequence=2\&isAllowed=y

- BRAge CAMAZANO, J., Doménech Pascual, Gabriel, Bienestar animal contra derechos 
fundamentales, en Boletín Mexicano de Derecho Comparado, Volumen 41 (2008) 1117-1123. http://www.scielo.org.mx/pdf/bmdc/v41n122/v41n122a22.pdf

- BAGNI, S., Los derechos de la naturaleza en la jurisprudencia colombiana e indiana, en Revista Jurídica de Derecho, Volumen 7 (2018) 33-53.

- MARTÍNEZ E. y ACOSTA A., Los derechos de la naturaleza como puerta de entrada a otro mundo posible, en Revista Direito e Práxis, Vol. 8 (2001) 2927-2961.

- REGAN, T., En defensa de los derechos de los animales (México 2016) 369.

- MOLINA ROA, J., Los derechos de los animales. De la cosificación a la zoopolítica, (Colombia 2018).

- GOMEZ PELLÓN E., Los problemas del patrimonio inmaterial: uso y abuso de los animales en España, en Revista de Antropología Iberoamericana, Vol. 12 (Madrid 2017) 147-168.

- SÁNCHEZ GONZÁlEZ, M.A., El debate ético actual sobre la relación del hombre con los animales, en Los derechos de los animales (Madrid 2002).

- EUROPAPRESS. Jane Goodall: "Nuestra falta de respeto a los animales ha causado la pandemia de coronavirus". Página Web: https://www.europapress.es/cultura/cine-00128/noticia-jane-goodallfalta-respeto-animales-causado-pandemia-coronavirus-20200416133432.html [Última consulta: 24 de mayo de 2020]

- PROJECT SYNDICATE. El otro lado oscuro del Covid-19. Página Web: http://www.projectsyndicate.org/commentary/wet-markets-breeding-ground-for-new-coronavirus-by-peter-singerand-paola-cavalieri-2020-03/spanish [última consulta: 27 de mayo de 2020]

- ORGANIZACIÓN DE NACIONES UNIDAS. Armonía con la naturaleza. Informe del Secretario General. Página Web: https://undocs.org/es/A/75/266 [Última consulta: 12 de agosto de 2020]

- OVIDIO, Las metamorfosis (Madrid 2012).

\section{Fuentes Legislativas}

- Convención Americana sobre Derechos Humanos. Página Web: https://www.oas.org/dil/esp/tratados_b-32_convencion_americana_sobre_derechos_humanos.htm [Última consulta: 3 de noviembre de 2020].

- Constitución Política de la Ciudad de México. Página Web: http://www.infodf.org.mx/documentospdf/constitucion_cdmx/Constitucion_\%20Politica_CDMX. pdf [Última consulta 27 de mayo de 2020].

- LOI n 2015-177 du 16 février 2015 relative à la modernisation et à la simplification du droit et des procédures dans les domaines de la justice et des affaires intérieures. Véase Pagina Web: https://www.legifrance.gouv.fr/jorf/id/JORFTEXT000030248562/ [Última consulta: 4 de noviembre de 2020]

\section{Fuentes jurisprudenciales}

- Sistema Argentino de información jurídica SAIJ. Página web http://www.saij.gob.ar/2786-nacionalprohibicion-malos-tratos-animales-lns0002465-1891-07-25/123456789-0abc-defg-g5642000scanyel [Última consulta 26 de mayo, 2020].

- Suprema Corte de Justicia de la Nación. Amparo en revisión 163/2018 [México]. Última consulta 24 de mayo de $2020 \mathrm{https} / / / \mathrm{www}$. scjn.gob.mx/sites/default/files/listas/documento_dos/201810/AR-163-2018-181022.pdf [Última consulta: 22 de mayo de 2020].

- Infojus: NV9953 [Http://www.infojus.gob.ar/camara-federal-casacion-penal-consideraunaorangutana-sumatra-es-sujeto-derechos-nv9953-2014-12-18/123456789-0abc-d35-99tilpssedadevon. [Última consulta 24 de mayo de 2020].

- Poder Judicial Federal. Juzgado Décimo Séptimo del Estado de Veracruz. México. Expediente 1303/2016. Sentencia de Juicio de Amparo. [Última consulta: 19 de mayo de 2020]. 